Check for updates

Cite this: Chem. Sci., 2019, 10, 10647

๑ All publication charges for this article have been paid for by the Royal Society of Chemistry

Received 13th September 2019

Accepted 4th October 2019

DOI: $10.1039 / \mathrm{c} 9 \mathrm{sc} 04624 \mathrm{k}$

rsc.li/chemical-science

\section{Hydration of nitriles using a metal-ligand cooperative ruthenium pincer catalyst $\uparrow$}

\author{
Beibei Guo, ${ }^{a}$ Johannes G. de Vries (iD) ${ }^{b}$ and Edwin Otten (iD *a \\ Nitrile hydration provides access to amides that are important structural elements in organic chemistry. \\ Here we report catalytic nitrile hydration using ruthenium catalysts based on a pincer scaffold with \\ a dearomatized pyridine backbone. These complexes catalyze the nucleophilic addition of $\mathrm{H}_{2} \mathrm{O}$ to a wide \\ variety of aliphatic and (hetero)aromatic nitriles in ${ }^{t} \mathrm{BuOH}$ as solvent. Reactions occur under mild \\ conditions (room temperature) in the absence of additives. A mechanism for nitrile hydration is proposed \\ that is initiated by metal-ligand cooperative binding of the nitrile.
}

\section{Introduction}

Amides are an important class of compounds that occur in a large variety of biologically active compounds, polymers and synthetic intermediates, ${ }^{1}$ and a variety of synthetic methods have been developed for their formation. ${ }^{2}$ Nitrile hydration provides an atom-efficient synthesis of amides and is carried out on an industrial scale, for example in the production of acrylamide $^{3}$ and nicotinamide. ${ }^{4}$ The direct nucleophilic addition of water to the $\mathrm{C} \equiv \mathrm{N}$ bond is kinetically slow, and a variety of catalysts have been developed, but it is often difficult to prevent over-hydrolysis to the corresponding carboxylic acids. ${ }^{5}$ Nitrile hydratase enzymes yield amides with excellent selectivity, ${ }^{6}$ but the limited substrate scope prevents their widespread use. There has been significant recent interest in the development of nitrile hydration catalysts based on transition metals, but most systems reported to date still require relatively high temperatures to reach appreciable catalytic turnover. ${ }^{7}$ Recent progress with $\mathrm{Rh}(\mathrm{I}),{ }^{8} \mathrm{Ru}(\mathrm{II}),{ }^{9} \mathrm{Pd}(\mathrm{II}),{ }^{10}$ and $\mathrm{Pt}(\mathrm{II})^{11}$ catalysts has allowed catalytic nitrile hydration under mild conditions, but additives are often required for high activity (e.g., AgOTf in Grubbs' Pt(II)/phosphinous acid catalysts, ${ }^{11}$ or $\mathrm{Sc}(\mathrm{OTf})_{3}$ in Yin's $\operatorname{Pd}\left(\right.$ II) catalysts $\left.{ }^{10}\right)$.

Metal complexes with pincer ligands have found widespread use in a large variety of catalytic reactions, ${ }^{12}$ but the incorporation of a reactive fragment in the ligand backbone to enable 'bifunctional' or 'cooperative' substrate binding/activation has only recently started to emerge. ${ }^{13}$ Examples include the (reversible) binding of unsaturated fragments such as $\mathrm{CO}_{2}{ }^{14}$ $\mathrm{SO}_{2},{ }^{15}$ carbonyl compounds, ${ }^{16}$ or nitriles. ${ }^{17}$ Our group reported

${ }^{a}$ Stratingh Institute for Chemistry, University of Groningen, Nijenborgh 4, 9747 AG Groningen, The Netherlands. E-mail: edwin.otten@rug.nl

${ }^{b}$ Leibniz-Institut für Katalyse e. $V$. an der Universität Rostock, Albert-Einstein-Strasse 29a, 18059 Rostock, Germany

$\dagger$ Electronic supplementary information (ESI) available. See DOI: $10.1039 / \mathrm{c} 9 \mathrm{sc} 04624 \mathrm{k}$ that Milstein's dearomatized Ru PNN pincer complex $\mathbf{A}^{\mathbf{P N N}}$ (Scheme 1, left) catalyzes the conjugate addition of alcohols to $\alpha, \beta$-unsaturated nitriles via a metal-ligand cooperative (MLC) mechanism by activation of the nitrile $\mathrm{C} \equiv \mathrm{N}$ bond. ${ }^{18}$ Very recently, similar reactivity was observed with a related $\mathrm{Mn}$ catalyst. ${ }^{19}$ This mode of activation reduces the bond order from 3 in the nitrile $(\mathrm{C} \equiv \mathrm{N})$ to 2 in the MLC intermediate $(-\mathrm{C}=\mathrm{N}-\mathrm{Ru})$, which significantly alters the reactivity profile of the substrate.

Having established that conjugate (1,4-) addition of weak alcohol nucleophiles is enabled by metal-ligand cooperation, we hypothesized that also 1,2-additions to MLC-activated nitriles may be feasible. Herein we describe our results on catalytic nitrile hydration using Ru complexes with dearomatized pyridine-based pincer ligands, and demonstrate that a large variety of aliphatic and (hetero)aromatic nitriles is

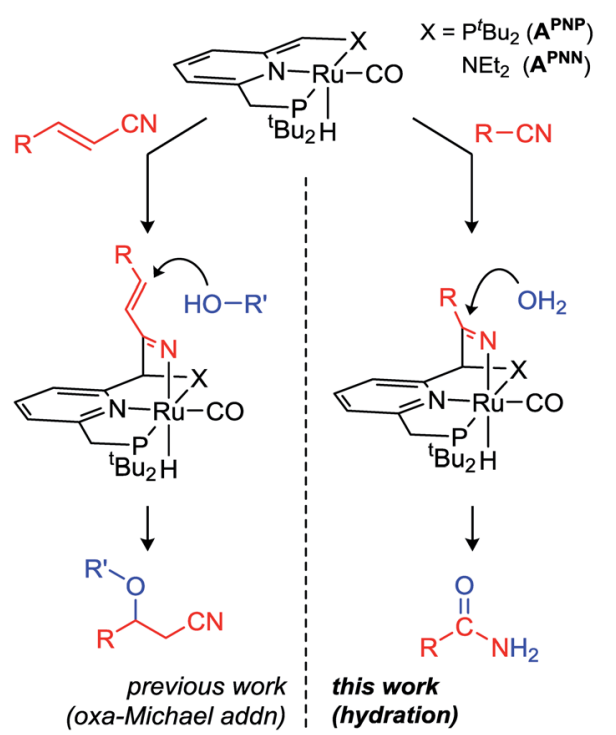

Scheme 1 MLC activation of nitriles towards addition of Onucleophiles. 
selectively converted to the corresponding amides under very mild conditions.

\section{Results and discussion}

\section{Catalyst development and reaction scope}

Previously it was found that the direct conjugate addition of $\mathrm{H}_{2} \mathrm{O}$ to $\alpha, \beta$-unsaturated nitriles was sluggish using catalyst $\mathbf{A}^{\mathbf{P N N}}{ }^{18 c}$ However, for some of the substrates tested we noticed that amides were obtained in low yield by hydration of the nitrile moiety. Encouraged by these observations, we initiated a screening of reaction conditions for the hydration of acetonitrile. These initial results (see ESI†) showed that both PNN complex $\mathbf{A}^{\mathbf{P N N}}$ and the symmetrical PNP analogue $\mathbf{A}^{\mathbf{P N P}}$ are active, and performed best in ${ }^{t} \mathrm{BuOH}$ solvent. An optimum in catalyst activity was found when 5 equivalents of $\mathrm{H}_{2} \mathrm{O}$ were added, which gave $63 \%$ conversion to acetamide after $24 \mathrm{~h}$ at room temperature $\left(3 \mathrm{~mol} \%\right.$ catalyst $\mathbf{A}^{\mathbf{P N P}}$ ). Repeating these reactions with either 2 or 8 equiv. of $\mathrm{H}_{2} \mathrm{O}$ present gave lower nitrile conversions of 44 and $42 \%$, respectively, and the reaction is almost completely suppressed in the presence of 20 equiv. of $\mathrm{H}_{2} \mathrm{O}(4 \%$ conversion after $24 \mathrm{~h})$. In view of the propensity of complexes such as A to heterolytically cleave $\mathrm{OH}$ bonds (including $\mathrm{H}_{2} \mathrm{O}$ ) in a reversible manner, ${ }^{20}$ it is likely that the nitrile, $\mathrm{H}_{2} \mathrm{O}$ and other components in the reaction mixture compete for reaction with the dearomatized complexes $\mathbf{A}$, and the presence of increased amounts of water will result in a larger equilibrium concentration of Ru-hydroxides (vide infra). The decrease in catalyst activity at $\mathrm{H}_{2} \mathrm{O}$ amounts beyond the optimum (5 equiv.) indicates that in the present catalyst system, Ru-hydroxides are likely not the active species. Although a variety of transition metal hydroxide species have been reported to catalyze nitrile hydration, these often require elevated temperatures. ${ }^{21}$ Control experiments carried out in the absence of the dearomatized Ru pincer complexes, either with $3 \mathrm{~mol} \%$ $\mathrm{KO}^{t} \mathrm{Bu}$ or the ruthenium precursor to $\mathbf{A}^{\mathbf{P N P}}$ (the aromatic (PNP) $\mathrm{Ru}(\mathrm{H})(\mathrm{Cl})(\mathrm{CO})$ complex) led to no conversion, indicating that the metal-ligand cooperative character of $\mathbf{A}$ is important in this catalytic conversion.

We subsequently focused on examining the scope of substrates that underwent hydration to the amide using $\mathbf{A}^{\mathbf{P N P}}$ as catalyst (Table 1). A selection of substrates was also subjected to catalysis by the nonsymmetrical $\mathbf{A}^{\mathbf{P N N}}$ catalyst, which resulted in similar results (Table 1, entries in brackets).

Substrates with halogen substituents $(\mathbf{1 b}-\mathbf{f})$ as well as electron-withdrawing trifluoromethyl (1g) or aldehyde groups $(\mathbf{1 h})$ at the para-position all afforded the corresponding amides in quantitative isolated yields. In case of aldehyde $\mathbf{1 h}$, its poor solubility in ${ }^{t} \mathrm{BuOH}$ resulted in slow conversion under the standard conditions, but addition of THF as co-solvent afforded a homogeneous solution and resulted in facile amide formation. For the three bromo-substituted substrates (1d-f), conversion of the hindered ortho-isomer was sluggish at room temperature, but at $50{ }^{\circ} \mathrm{C}$ the reaction went to completion within 2 days. The hydration reaction also occurred with naphthylnitriles $(\mathbf{1} \mathbf{j}, \mathbf{k})$. The presence of an electron-withdrawing para-nitro substituent completely suppressed the reaction at
Table 1 Scope of nitrile hydration catalyzed by Ru pincer complex $\mathrm{A}^{\mathrm{PNP} a}$

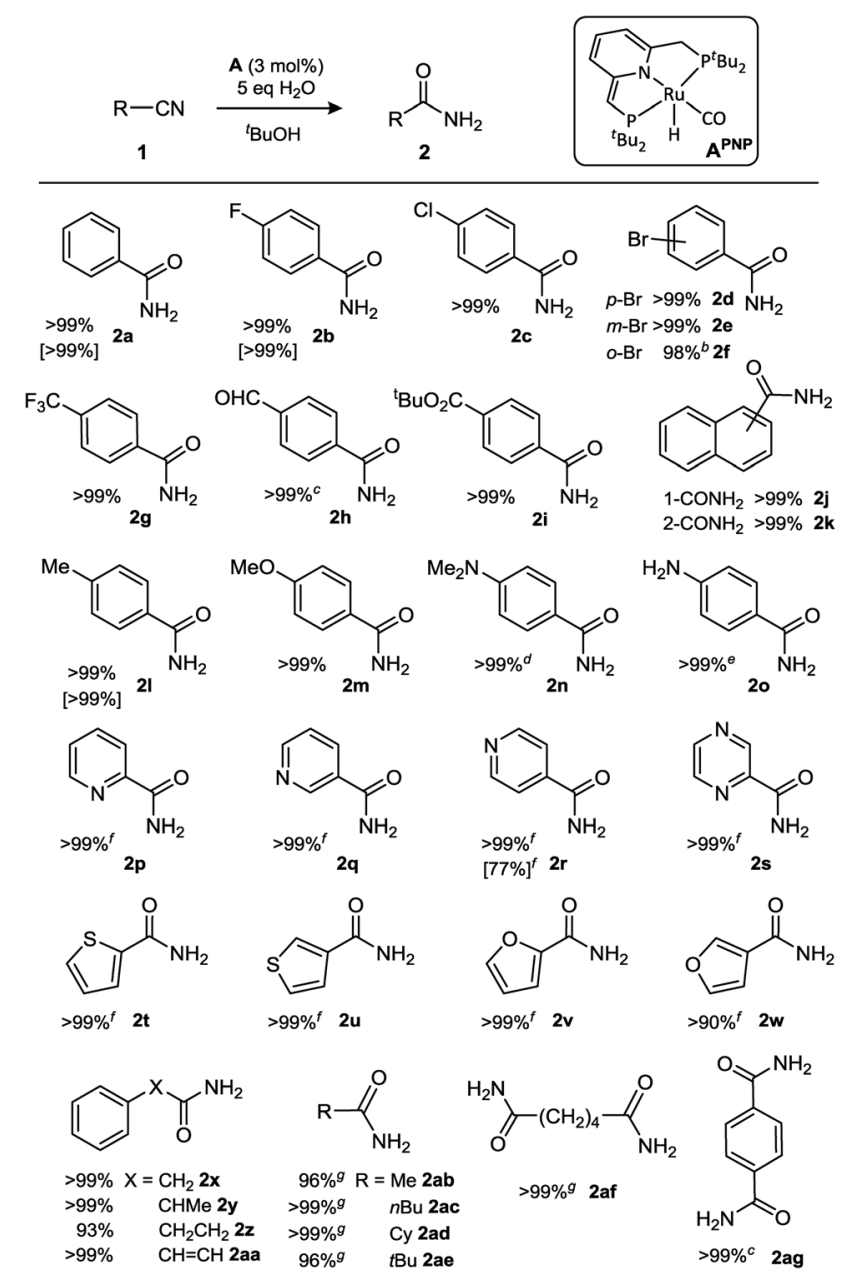

${ }^{a}$ Isolated yield after reaction at room temperature for 1 day, unless noted otherwise. Conversions using catalyst $\mathbf{A}^{\mathbf{P N N}}$ under the same conditions are given in square brackets. ${ }^{b}$ Reaction at $50{ }^{\circ} \mathrm{C}$ for 2 days. ${ }^{c}$ Reaction in a $1: 1$ mixture of $\mathrm{THF} /{ }^{t} \mathrm{BuOH}$ due to poor solubility of the starting material. ${ }^{d}$ Reaction at $50{ }^{\circ} \mathrm{C}$ for 20 hours. ${ }^{e}$ Reaction at $80{ }^{\circ} \mathrm{C}$ for 16 hours. ${ }^{f}$ Reaction at room temperature for 1 day with $0.5 \mathrm{~mol} \%$ catalyst loading. ${ }^{g}$ Reaction at $50{ }^{\circ} \mathrm{C}$ for 24 hours.

room temperature; heating to $80{ }^{\circ} \mathrm{C}$ restored some catalytic activity, but the reaction stalled at $c a .25 \%$ conversion under those conditions. Catalyst deactivation by the nitro-group does not seem to take place, as hydration of $\mathbf{1 b}$ in the presence of an equimolar amount of nitrobenzene gives full conversion to $\mathbf{2 b}$ at a rate that is similar to that in the absence of nitrobenzene (see ESI $\dagger$ ). A likely explanation is that the $p$-nitro benzamide product, which has a relatively acidic $\mathrm{N}-\mathrm{H}$ bond, competes with the nitrile substrate for binding with the catalyst and leads to product inhibition (vide infra). Benzonitriles with electrondonating substituents ( $p$-Me, -OMe, $-\mathrm{NR}_{2}$ ) are also hydrated, although the aniline derivatives required heating to achieve full conversion (1n: $50{ }^{\circ} \mathrm{C}$ for $20 \mathrm{~h}$; 10 : $80{ }^{\circ} \mathrm{C}$ for $16 \mathrm{~h}$ ). In the case of the free aniline 1o, this may be due to competing (reversible) $\mathrm{N}-\mathrm{H}$ bond activation to form Ru-anilido species. ${ }^{22}$ Consistent 
with this hypothesis is the observation that 4-hydroxybenzonitrile is not converted even at $80{ }^{\circ} \mathrm{C}$, indicating that the acidic $\mathrm{Ar}-$ $\mathrm{OH}$ moiety deactivates the catalyst in an irreversible manner. ${ }^{18 a, 23}$

Unhindered esters such as 4-acetoxybenzonitrile and ethyl 4cyanobenzoate also do not form the amide products, likely because of competing ester hydrolysis to the carboxylic acids. For more hindered esters, however, the reaction works well as demonstrated by full conversion of tert-butyl 4-cyanobenzoate (1i).

Heteroaromatic nitriles are also converted, with even shorter reaction times under the standard conditions ( $<1$ h with $3 \mathrm{~mol} \%$ catalyst $\mathbf{A}^{\mathbf{P N P}}$ ). Consequently, this class of substrates reaches full conversion within a day at room temperature using a catalyst loading of $0.5 \mathrm{~mol} \%$ (TON = 200). The ortho-, meta- and paraisomers of cyanopyridine (1p-r), as well as the pyrazine derivative (1s) are converted to the amide products in quantitative yields. Moreover, substrates with oxygen- (furan, 1t,u) or sulfurcontaining rings (thiophenes, $\mathbf{1 v}, \mathbf{w}$ ), structural motifs that are often considered catalyst poisons, underwent this rutheniumcatalyzed process with remarkable ease.

Substrates with $\mathrm{sp}^{3}-\mathrm{C}$ substituents adjacent to the $\mathrm{C} \equiv \mathrm{N}$ group react more slowly but nevertheless are converted with complete selectivity to the amide. For example, benzyl cyanide (1x) and its $\alpha$-methylated analogue (1y) show full conversion to the amide within 1 day at room temperature, and the same applies to 3-phenylpropionitrile $(\mathbf{1 z})$ and the $\mathrm{sp}^{2}$-substituted cinnamonitrile (1aa). While purely aliphatic nitriles also react at room temperature, these substrates require longer reaction times to reach synthetically useful conversions (65-83\% after 2 days). However, gentle heating of the reaction mixtures to $50{ }^{\circ} \mathrm{C}$ for 1 day affords amide products in $>99 \%$ isolated yield for primary, secondary as well as tertiary alkylnitriles (1ab-ae). Substrates with two nitrile moieties were selectively converted to the corresponding diamides (1af/1ag).

The substrates shown in Table 1 are converted by catalysts $\mathbf{A}$ already at room temperature (and many reach full conversion within $24 \mathrm{~h}$ ), but, with the exception of heteroaromatic nitriles, turnover numbers (TONs) for the majority of entries are only modest due to the presence of $3 \mathrm{~mol} \%$ catalyst (maximum TON =33). To examine whether higher turnover numbers can be obtained, we tested the reaction at elevated temperature $\left(70^{\circ} \mathrm{C}\right)$ for aromatic nitrile $\mathbf{1 b}$ and aliphatic dinitrile 1af. For $\mathbf{1 b}$, hydration is initially fast ( $63 \%$ conversion in $1 \mathrm{~h}$ ), but then gradually slows down to reach $98 \%$ conversion in $20 \mathrm{~h}$ under those conditions $(\mathrm{TON}=196)$. Dinitrile 1 af also gave $>98 \%$ conversion of the starting material in $24 \mathrm{~h}$ at $70{ }^{\circ} \mathrm{C}$ to afford a mixture of mono- and diamide products in a $57: 43$ ratio, which corresponds to a total nitrile TON of 307 . Moreover, with 3-cyanopyridine (1q) the catalyst reaches 1000 turnovers within a day at $70{ }^{\circ} \mathrm{C}$, demonstrating the robustness of the catalyst at elevated temperature.

\section{Mechanistic considerations}

To obtain insight in the species present during turnover, we monitored a catalysis reaction mixture $\left(3 \mathrm{~mol} \% \mathbf{A}^{\text {PNP }}, 5\right.$ eq. $\mathrm{H}_{2} \mathrm{O}$ in ${ }^{t} \mathrm{BuOH}$ ) with the fluoro-substituted benzonitrile $\mathbf{1 b}$ by ${ }^{19} \mathrm{~F}$ NMR spectroscopy. This showed the presence of three distinct ${ }^{19}$ F-containing species. Two of these correspond to the nitrile starting material and the amide product by comparison to authentic samples. A third species was present throughout the course of the reaction in minor amount $\left({ }^{19} \mathrm{~F}\right.$ NMR: $\delta-118 \mathrm{ppm}$, ca. $2.5 \%$ based on integration). This resonance was also observed in the ${ }^{19}$ F NMR of a catalysis mixture with $\mathbf{A}^{\mathbf{P N N}}$, suggesting that $\mathbf{A}^{\mathbf{P N P}}$ and $\mathbf{A}^{\mathbf{P N N}}$ lead to similar speciation under the reaction conditions.

To characterize this species and develop an understanding of the individual steps that might be involved in the catalysis, we carried out stoichiometric NMR scale experiments in THF- $d_{8}$ between the dearomatized pincer complexes $\mathbf{A}$ and the components present in the catalysis reaction mixture (see ESI for details $\dagger$ ). Analysis of a 1:1 mixture of complex $\mathbf{A}^{\mathbf{P N P}}$ and nitrile $\mathbf{1 b}$ by ${ }^{1} \mathrm{H}$ NMR spectroscopy showed a substantial broadening of the $\mathrm{Ru}-\mathrm{H}$ signal which is additionally shifted downfield by $c a .7 \mathrm{ppm}$, indicating a rapidly exchanging equilibrium between the starting materials and the Ru-nitrile adduct $\mathbf{B}^{\mathbf{P N P}}$ (Scheme 2). ${ }^{\mathbf{1 8 b}}$

The sterically less hindered PNN analogue $\mathbf{A}^{\mathbf{P N N}}$ reacts with nitrile $\mathbf{1 b}$ to an equilibrium mixture of $\mathbf{C}^{\mathbf{P N N}}$ and $\mathbf{C}^{\prime \mathbf{P N N}}$ according to NMR spectroscopy. In this mixture, a characteristic ${ }^{1} \mathrm{H}$ NMR resonance is observed at $\delta 11.65$ (singlet) for the $\mathrm{NH}$ fragment in $\mathbf{C}^{\mathbf{P N N}}$. Additionally, signals at $\delta-10.47 /$ $-13.75 \mathrm{ppm}$ (doublets, $J_{\mathrm{PH}}=25.7 / 32.8 \mathrm{~Hz}$ ) appear for the $\mathrm{Ru}-\mathrm{H}$ groups in $\mathbf{C}^{\prime \mathbf{P N N}} / \mathbf{C}^{\mathbf{P N N}}$. The NMR features are very similar to those observed previously by us for the reaction of $\mathbf{A}^{\mathbf{P N N}}$ and benzonitrile, ${ }^{18 b}$ and confirm that the latter products arise from MLC binding of the $\mathrm{C} \equiv \mathrm{N}$ bond. The different outcomes of the reaction between $\mathbf{1 b}$ and $\mathbf{A}^{\mathbf{P N N}}$ or $\mathbf{A}^{\mathbf{P N P}}$ indicates that the divergent steric demands of the PNP vs. PNN ligand affects the equilibria between species A, B and C. Although a detailed comparison between PNN- and PNP-based catalysts is beyond the scope of this research, preliminary DFT calculations indicate that MLC-binding of benzonitrile is exergonic at the $\mathrm{N}$-arm $\left(-2.7 \mathrm{kcal} \mathrm{mol}^{-1}\right)$ whereas it is endergonic at the P-arm (PNN:

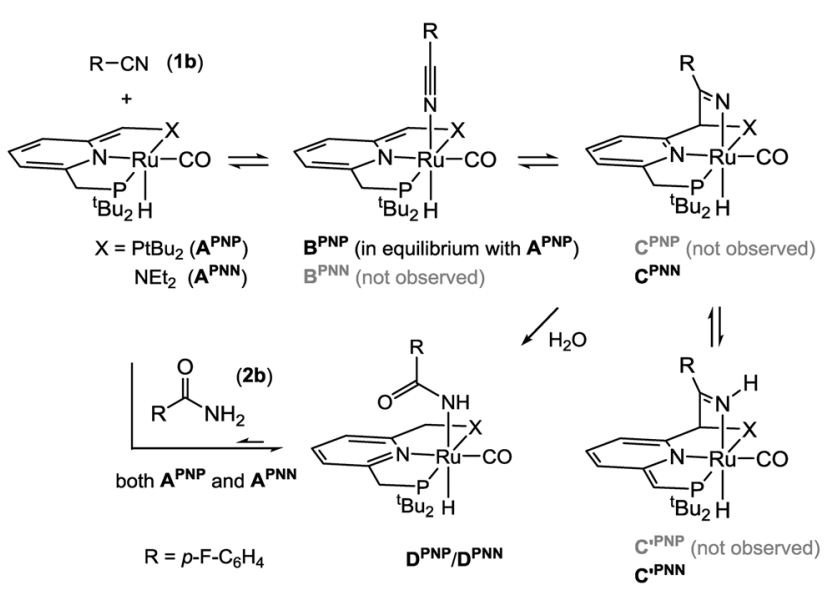

Scheme 2 Stoichiometric reactions between $\mathrm{A}$ and the components present in the reaction mixture. 
+9.4 kcal mol; PNP: +7.2 $\mathrm{kcal} \mathrm{mol}^{-1}$ ). It should be noted that, even though the relative stability of the various intermediates is sensitive to steric effects, metal-ligand cooperative reaction pathways are involved in complexes with both these ligands. ${ }^{\mathbf{2 4}}$

Regardless of the different equilibrium compositions, addition of $\mathrm{H}_{2} \mathrm{O}$ ( 1 equiv.) to a THF- $d_{8}$ solution of both the PNN- or PNP-based mixture resulted in the slow appearance of a new species (D) with a ${ }^{19} \mathrm{~F}$ NMR shift (ca. $\left.\delta-118 \mathrm{ppm}\right)$ that agrees well with the one observed during catalysis in ${ }^{t} \mathrm{BuOH}$. Compounds $\mathbf{D}$ were also obtained cleanly by treatment of the dearomatized $\mathbf{R u}$ pincer complexes $\mathbf{A}$ with amide $\mathbf{2} \mathbf{b}$, and are formulated as Ru-carboxamides $\left(\mathbf{D}^{\mathbf{P N N}} / \mathbf{D}^{\mathbf{P N P}}\right.$, Scheme 2) on the basis of their NMR spectra (see ESI $\dagger$ ).

The observation that $\mathbf{D}$ is the dominant Ru-containing species during turnover suggests that it may be a dormant catalyst state, and that catalysis could be subject to product inhibition. Indeed, when a mixture of nitrile substrate and amide product (33 and 10 equiv., respectively, relative to $\mathbf{A}^{\mathbf{P N P}}$ ) is present at the start, the reaction rate is decreased but full conversion is still obtained (see ESI $\dagger$ ). Also, when $\mathbf{D}^{\mathbf{P N P}}$ is prepared independently and tested in catalysis, hydration of $\mathbf{1 b}$ occurs with a rate that is qualitatively similar to that with $\mathbf{A}^{\mathbf{P N P}}$.

These observations indicate that the coordinatively saturated complex $\mathbf{D}$ is able to generate the active species via a rapid equilibrium with $\mathbf{A}$. This was further confirmed by the observation that $\mathbf{D}^{\mathbf{P N N}}$ reacts with nitrile $\mathbf{1 b}$ to regenerate the equilibrium mixture of $\mathbf{C}^{\mathbf{P N N}}$ and $\mathbf{C}^{\prime \mathbf{P N N}}$, a reaction that presumably involves $\mathbf{A}^{\mathbf{P N N}}$ as an intermediate (Scheme 2). For the PNP analogue, the concentration of $\mathbf{D}^{\mathbf{P N P}}$ decreases upon addition of $\mathrm{H}_{2} \mathrm{O}$, and NMR resonances attributable to the free amide $\mathbf{2 b}$ appear. From these data it is clear that the catalyst speciation in this system is complex: the dearomatized pincer complexes $\mathbf{A}$ are involved in dynamic equilibria with $\mathrm{H}_{2} \mathrm{O}$, nitrile, as well as amide. Thus, even though under the reaction conditions most of the Ru is present in a coordinatively saturated, inactive form (D), access to catalytically active species is kinetically facile and allows turnover of the nitrile substrate.

Mechanistic proposals for catalytic nitrile hydration in the literature often involve Lewis acid activation of the nitrile, sometimes in conjunction with ligand-mediated ('bifunctional') deprotonation of $\mathrm{H}_{2} \mathrm{O},{ }^{25,26}$ or nucleophilic attack of a reactive ligand-OH fragment (e.g., in catalysts with phosphinous acid ligands). ${ }^{27}$ For bimetallic complexes, a reactive metal-hydroxide group can be generated adjacent to a metal-nitrile adduct, which provides a low-energy pathway to hydration. ${ }^{28}$

On the basis of the results discussed above, we propose that the mechanism of nitrile hydration by $\mathbf{A}$ is distinct and follows the steps illustrated in Scheme 3. Under the reaction conditions, complexes A react reversibly with amide or $\mathrm{H}_{2} \mathrm{O}$ to form the off-cycle species $\mathbf{D}$ and $\mathbf{E}$, respectively. Although these species are not catalytically relevant, a rapid equilibrium between these dormant states and A ensures an entry into the catalytic cycle. We propose that catalysis is initiated by MLC binding of the nitrile substrate (1) to form $\mathbf{C}$. The MLC mode of $\mathrm{C} \equiv \mathrm{N}$ bond activation results in a reduced $\mathrm{CN}$ bond order of 2 , and transfers the basicity 'stored' in the pincer framework in A onto the nitrile-derived $\mathrm{Ru}-\mathrm{N}$ moiety in $\mathrm{C}$. This allows

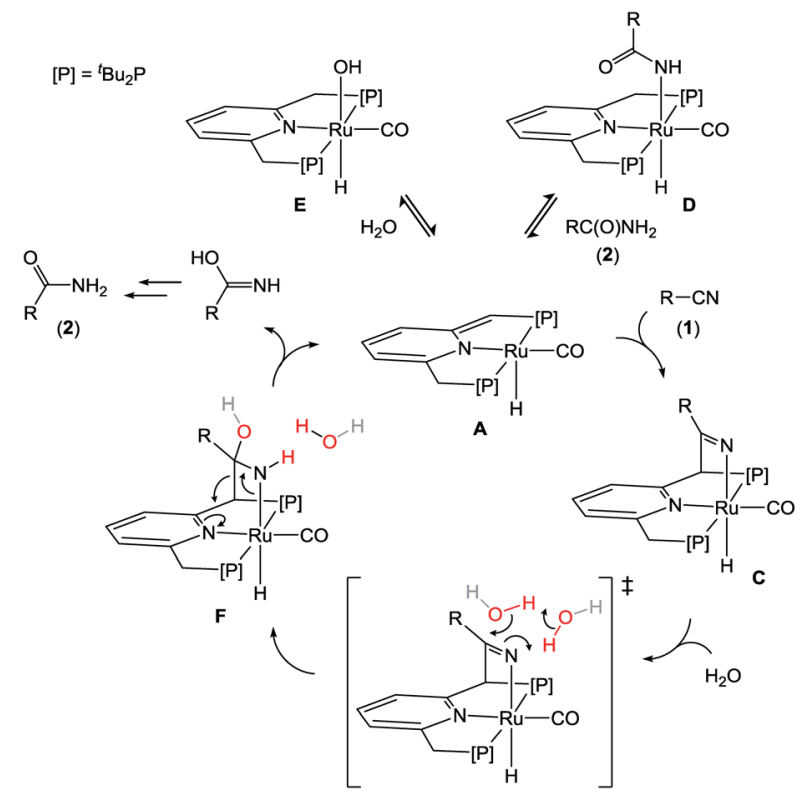

Scheme 3 Proposed catalytic cycle.

deprotonation of the pro-nucleophile $\mathrm{H}_{2} \mathrm{O}$ and attack at the electrophilic C-atom of the activated nitrile to form $\mathbf{F}$, either directly or facilitated by a hydrogen-bond network involving additional $\mathrm{H}_{2} \mathrm{O}$ or ${ }^{t} \mathrm{BuOH}$ as proton-shuttles. ${ }^{29,27 b}$ The coordinated hydroxyamido fragment in intermediate $\mathbf{F}$ may be liberated from the metal complex by a retro-cycloaddition to form the iminol, which tautomerizes in solution to the final amide product (2). Alternative pathways that directly convert $\mathbf{F}$ to the Ru-carboxamide $\mathbf{D}$ cannot be ruled out at present. The proposed reaction pathway accounts for several key experimental observations, including (i) the requirement for a reactive ligand site for catalytic activity, (ii) an optimum in catalyst activity as function of the amount of water added, (iii) and the occurrence of product inhibition.

\section{Conclusions}

In summary, this work describes an efficient homogeneous catalyst for the hydration of nitriles. Complexes based on dearomatized PNP or PNN ligands are shown to be active under very mild reaction conditions (ambient temperature, additivefree). The PNP Ru pincer catalyst is tolerant to a variety of functional groups, and allows the hydration of a broad range of aliphatic, aromatic and heteroaromatic nitriles. On the basis of stoichiometric experiments, a mechanism is proposed that involves metal-ligand cooperative activation of the nitrile $\mathrm{C} \equiv \mathrm{N}$ bond. The results suggest that the generation of intermediates with a $\mathrm{C}=\mathrm{N}$ moiety (i.e., a reduced bond order in comparison to the nitrile starting material) via this mode of nitrile activation significantly increases its reactivity and leads to facile attack by (pro)nucleophiles as weak as $\mathrm{H}_{2} \mathrm{O}$. We anticipate that this strategy may be more broadly applicable and lead to novel reactivity of nitriles and other unsaturated organic compounds. A more detailed examination of the catalytic reaction 
mechanism, as well as modification of the catalyst to increase productivity (e.g., by minimizing product inhibition) are ongoing in our laboratory.

\section{Conflicts of interest}

There are no conflicts to declare.

\section{Acknowledgements}

Financial support from the Netherlands Organisation for Scientific Research (NWO) (VIDI grant to EO) and the China Scholarship Council (grant to BG) is gratefully acknowledged. We would like to thank the Center for Information Technology of the University of Groningen for their support and for providing access to the Peregrine high performance computing cluster.

\section{Notes and references}

1 (a) J. S. Carey, D. Laffan, C. Thomson and M. T. Williams, Org. Biomol. Chem., 2006, 4, 2337-2347; (b) D. J. C. Constable, P. J. Dunn, J. D. Hayler, G. R. Humphrey, J. J. L. Leazer, R. J. Linderman, K. Lorenz, J. Manley, B. A. Pearlman, A. Wells, A. Zaks and T. Y. Zhang, Green Chem., 2007, 9, 411-420.

2 (a) C. L. Allen and J. M. J. Williams, Chem. Soc. Rev., 2011, 40, 3405-3415; (b) V. R. Pattabiraman and J. W. Bode, Nature, 2011, 480, 471.

3 T. Ohara, T. Sato, N. Shimizu, G. Prescher, H. Schwind, O. Weiberg, K. Marten and H. Greim, in Ullmann's Encyclopedia of Industrial Chemistry, 2011, DOI: 10.1002/ 14356007.a01_161.pub3.

4 R. Blum, in Ullmann's Encyclopedia of Industrial Chemistry, 2015, pp. 1-9.

5 (a) C. O'Connor, Q. Rev., Chem. Soc., 1970, 24, 553-564; (b) T. Tu, Z. Wang, Z. Liu, X. Feng and Q. Wang, Green Chem., 2012, 14, 921-924.

6 (a) M. Kobayashi and S. Shimizu, Nat. Biotechnol., 1998, 16, 733; (b) P. K. Mascharak, in Molecular Design in Inorganic Biochemistry, ed. D. Rabinovich, Springer-Verlag, Berlin, Heidelberg, 2014, pp. 89-113; (c) J.-S. Gong, J.-S. Shi, Z.-M. Lu, H. Li, Z.-M. Zhou and Z.-H. Xu, Crit. Rev. Biotechnol., 2017, 37, 69-81.

7 (a) S.-I. Murahashi and H. Takaya, Acc. Chem. Res., 2000, 33, 225-233; (b) V. Y. Kukushkin and A. J. L. Pombeiro, Inorg. Chim. Acta, 2005, 358, 1-21; (c) T. J. Ahmed, S. M. M. Knapp and D. R. Tyler, Coord. Chem. Rev., 2011, 255, 949-974; (d) R. García-Álvarez, J. Francos, E. TomásMendivil, P. Crochet and V. Cadierno, J. Organomet. Chem., 2014, 771, 93-104; (e) E. L. Downs and D. R. Tyler, Coord. Chem. Rev., 2014, 280, 28-37.

8 A. Goto, K. Endo and S. Saito, Angew. Chem., Int. Ed., 2008, 47, 3607-3609.

9 M. Nirmala, G. Saranya and P. Viswanathamurthi, Inorg. Chim. Acta, 2016, 442, 134-144.
10 S. Zhang, H. Xu, C. Lou, A. M. Senan, Z. Chen and G. Yin, Eur. J. Org. Chem., 2017, 2017, 1870-1875.

11 X. Xing, C. Xu, B. Chen, C. Li, S. C. Virgil and R. H. Grubbs, J. Am. Chem. Soc., 2018, 140, 17782-17789.

12 (a) G. Van Koten and D. Milstein, Organometallic Pincer Chemistry, Springer Berlin Heidelberg, 2013; (b) D. Morales-Morales, Pincer Compounds: Chemistry and Applications, Elsevier, 2018.

13 (a) C. Gunanathan and D. Milstein, Chem. Rev., 2014, 114, 12024-12087; (b) J. R. Khusnutdinova and D. Milstein, Angew. Chem., Int. Ed., 2015, 54, 12236-12273; (c) H. Li, T. P. Gonçalves, D. Lupp and K.-W. Huang, ACS Catal., 2019, 9, 1619-1629; (d) J. I. van der Vlugt, in Pincer Compounds: Chemistry and Applications, ed. D. MoralesMorales, Elsevier, 2018, pp. 599-621.

14 (a) C. A. Huff, J. W. Kampf and M. S. Sanford, Organometallics, 2012, 31, 4643-4645; (b) M. Vogt, M. Gargir, M. A. Iron, Y. Diskin-Posner, Y. Ben-David and D. Milstein, Chem.-Eur. J., 2012, 18, 9194-9197; (c) M. Feller, U. Gellrich, A. Anaby, Y. Diskin-Posner and D. Milstein, J. Am. Chem. Soc., 2016, 138, 6445-6454; (d) M. Feller, E. Ben-Ari, Y. Diskin-Posner and D. Milstein, J. Coord. Chem., 2018, 71, 1679-1689.

15 R. Stichauer and M. Vogt, Organometallics, 2018, 37, 36393643.

16 C. A. Huff, J. W. Kampf and M. S. Sanford, Chem. Commun., 2013, 49, 7147-7149.

17 (a) A. Nerush, M. Vogt, U. Gellrich, G. Leitus, Y. Ben-David and D. Milstein, J. Am. Chem. Soc., 2016, 138, 6985-6997; (b) M. Vogt, A. Nerush, M. A. Iron, G. Leitus, Y. DiskinPosner, L. J. W. Shimon, Y. Ben-David and D. Milstein, J. Am. Chem. Soc., 2013, 135, 17004-17018; (c) G. A. Filonenko, E. Cosimi, L. Lefort, M. P. Conley, C. Copéret, M. Lutz, E. J. M. Hensen and E. A. Pidko, ACS Catal., 2014, 4, 2667-2671.

18 (a) S. Perdriau, D. S. Zijlstra, H. J. Heeres, J. G. de Vries and E. Otten, Angew. Chem., Int. Ed., 2015, 54, 4236-4240; (b) L. E. Eijsink, S. C. P. Perdriau, J. G. de Vries and E. Otten, Dalton Trans., 2016, 45, 16033-16039; (c) B. Guo, D. S. Zijlstra, J. G. de Vries and E. Otten, ChemCatChem, 2018, 10, 2868-2872.

19 S. Tang and D. Milstein, Chem. Sci., 2019, DOI: 10.1039/ c9sc03269j.

$20(a)$ S. W. Kohl, L. Weiner, L. Schwartsburd, L. Konstantinovski, L. J. W. Shimon, Y. Ben-David, M. A. Iron and D. Milstein, Science, 2009, 324, 74-77; (b) C. L. Mathis, J. Geary, Y. Ardon, M. S. Reese, M. A. Philliber, R. T. VanderLinden and C. T. Saouma, J. Am. Chem. Soc., 2019, 141, 14317-14328.

21 (a) J. Chin and J. H. Kim, Angew. Chem., Int. Ed., 1990, 29, 523-525; (b) N. H. Anderson, J. M. Boncella and A. M. Tondreau, Organometallics, 2018, 37, 4675-4684.

22 E. Khaskin, M. A. Iron, L. J. W. Shimon, J. Zhang and D. Milstein, J. Am. Chem. Soc., 2010, 132, 8542-8543.

23 S. Perdriau, M.-C. Chang, E. Otten, H. J. Heeres and J. G. de Vries, Chem.-Eur. J., 2014, 20, 15434-15442. 
24 (a) H. Li and M. B. Hall, ACS Catal., 2015, 5, 1895-1913; (b) C. Hou, Z. Zhang, C. Zhao and Z. Ke, Inorg. Chem., 2016, 55, 6539-6551.

25 (a) R. García-Álvarez, J. Díez, P. Crochet and V. Cadierno, Organometallics, 2010, 29, 3955-3965; (b) S. M. M. Knapp, T. J. Sherbow, R. B. Yelle, J. J. Juliette and D. R. Tyler, Organometallics, 2013, 32, 3744-3752; (c) W.-C. Lee, J. M. Sears, R. A. Enow, K. Eads, D. A. Krogstad and B. J. Frost, Inorg. Chem., 2013, 52, 1737-1746; (d) S. M. M. Knapp, T. J. Sherbow, R. B. Yelle, L. N. Zakharov, J. J. Juliette and D. R. Tyler, Organometallics, 2013, 32, 824834; (e) M. K. Rong, K. van Duin, T. van Dijk, J. J. M. de Pater, B.-J. Deelman, M. Nieger, A. W. Ehlers, J. C. Slootweg and K. Lammertsma, Organometallics, 2017, 36, 1079-1090; ( $f$ ) R. González-Fernández, P. Crochet and V. Cadierno, ChemistrySelect, 2018, 3, 4324-4329.

26 (a) T. Oshiki, H. Yamashita, K. Sawada, M. Utsunomiya, K. Takahashi and K. Takai, Organometallics, 2005, 24, 6287-6290; (b) P. Daw, A. Sinha, S. M. W. Rahaman, S. Dinda and J. K. Bera, Organometallics, 2012, 31, 3790-
3797; (c) K. Singh, A. Sarbajna, I. Dutta, P. Pandey and J. K. Bera, Chem.-Eur. J., 2017, 23, 7761-7771.

27 (a) T. Ghaffar and A. W. Parkins, Tetrahedron Lett., 1995, 36, 8657-8660; (b) E. Tomás-Mendivil, V. Cadierno, M. I. Menéndez and R. López, Chem.-Eur. J., 2015, 21, 16874-16886; (c) R. González-Fernández, P. Crochet, V. Cadierno, M. I. Menéndez and R. López, Chem.-Eur. J., 2017, 23, 15210-15221.

28 (a) C. J. McKenzie and R. Robson, J. Chem. Soc., Chem. Commun., 1988, 112-114; (b) E. C. Wilkinson, Y. Dong and L. Que, J. Am. Chem. Soc., 1994, 116, 8394-8395; (c) F. Meyer, E. Kaifer, P. Kircher, K. Heinze and H. Pritzkow, Chem.-Eur. J., 1999, 5, 1617-1630; (d) P. J. Zinn, T. N. Sorrell, D. R. Powell, V. W. Day and A. S. Borovik, Inorg. Chem., 2007, 46, 10120-10132.

29 (a) M. A. Iron, E. Ben-Ari, R. Cohen and D. Milstein, Dalton Trans., 2009, 9433-9439; (b) J. Li, Y. Shiota and K. Yoshizawa, J. Am. Chem. Soc., 2009, 131, 13584-13585; (c) S. Qu, Y. Dang, C. Song, M. Wen, K.-W. Huang and Z.-X. Wang, J. Am. Chem. Soc., 2014, 136, 4974-4991. 